\title{
"We need to talk about what race feels like!" Using memory work to analyse the production of race and ethnicity in research encounters
}

\author{
madeleine kennedy-macfoy and Helene Pristed Nielsen
}

\begin{abstract}
This article is about the production of race and ethnicity in research encounters. It is based on a type of retrospective, comparative memory work, through which we analyse, compare and contrast our respective experiences of moments when race and ethnicity have been produced during our interactions with research participants. We suggest that adding memory work to the analysis of research experiences is one way of exposing the production of race and ethnicity in research interactions, and that a comparative approach to memory work can help clarify how positionalities may not always be good predictors of processes of racialisation in research situations. We also suggest that by looking for instances in which we have felt (or been made to feel) our own 'difference' or 'sameness', power or a sense disorientation, we may contribute to destabilising the categories and categorisations, which might otherwise go unquestioned in research encounters. Our analysis makes clear how we cannot assume any fixation of where, in whom, or in which topics race or ethnicity is located. We suggest that memory work is a useful tool for learning about the production of race and ethnicity, and comparative or contrastive memory work in collaboration with other researchers differently positioned from oneself is a useful approach when engaging in 'researching differences'.
\end{abstract}

Keywords: feminist memory work, race, ethnicity, racialization, difference, sameness

Please cite this article as: kennedy-macfoy, $\mathrm{m}$. and Pristed Nielsen, H. (2012). "We need to talk about what race feels like!" Using memory work to analyse the production of race and ethnicity in research encounters. Qualitative Studies, 3(2): 133-149.

\section{Introduction}

We (Helene and madeleine, the authors of this article) met at a conference in Sigtuna in Sweden in the autumn of 2010. As we discussed the morning's presentations on the first day of the conference, and made our way to lunch, our conversation turned to our respective experiences of conducting interviews with people who were, a priori, positioned as 'different' from or the 'same' as us in terms of race or ethnicity. As we spoke about the research encounters we had each experienced, we agreed that it would be interesting to extend our dialogue about how each of us had experienced the production of race and ethnicity in our research encounters, given our different positionalities vis-à-vis race, as we both felt we could learn more from such a dialogue. Following the tradition of much feminist scholarship, we wanted to reflect on the research process as not remaining untouched by our own 'intellectual autobiography' (Maynard, 1994: 16). However, our aim is to get beyond "examining [our] individual identities [as] researchers", and focus instead on "how such identities intersect with institutional, geopolitical and material aspects of [our racialised and ethnic] positionality" (Nagar \& Geiger, 2007: 2) in research interactions.

Feminist researchers, inspired in the first instance by the work of Haug and her colleagues during the late 1980s, have developed a methodological research tool or approach most commonly referred to as 'memory work' (see Haug et al. 1987). Jansson et al. argue that: "In many ways, memory work is in line with the feminist epistemological critique of conventional 
understandings of the scientific researcher as an objective and distanced observer of the world/the object of study" (2008: 231). In practice, doing memory work "involves the writing of personal memories of particular episodes related to the topic under investigation" (Berg, 2008:216). Commonly, the reason for doing memory work is to use the analysis of the memories to inform the theoretical framing for a piece of research, or the analysis of research findings (Berg, 2008). So memory work usually takes place prior to, or as part of the research.

The article builds on research by Nordic researchers in which feminist memory work is employed, especially Berg's (joint) work on using memory work in research on processes of racialisation (see Berg, 2008). We add a comparative dimension to Berg's approach, and further expand it to cover the related, though different, theme of ethnicity. Our added comparative dimension highlights the differences and similarities between how race or ethnicity is produced in research interactions when the researcher is racialised as black (madeleine) or white (Helene). However, the type of memory work that this article is based on differs from the traditional approach to memory work, as explained by Berg. The article is based on a type of retrospective, comparative memory work, through which we analyse, compare and contrast our experiences of moments when race and ethnicity have been produced during our interactions within research settings. We have chosen to engage in memory work in this way because we are interested, firstly, in problematising our naturalised (racialised or ethnic) positions, in order to "learn more about the production of race" (Berg, 2008: 220) and ethnicity. Secondly, we are keen to draw comparisons and contrasts between our respective research experiences in order to tease out some of the nuances of 'difference within sameness' and 'sameness within difference' that can often be overlooked when discussing the production of race or ethnicity simply from one position (such as, black or white, Danish or British Sierra Leonean). Through the joint analysis of our own and each other's memories, we aim to problematise our own and our interlocutors' assumptions about positionality (theirs and ours), and how these assumptions produce meanings about race or ethnicity in research encounters.

Following Alcoff, we view positionality as "a location for the construction of meaning, a place from where meaning is constructed, rather than simply the place where meaning can be discovered" (Alcoff, 1988:434, emphasis in the original). Accordingly, positionality necessarily frames and has an impact on whom and what we research, as well as informing how we conduct and analyse our findings; indeed, positionality determines to a greater or lesser extent, why we do research at all. Our focus here, however, is on the relationship between our positionality, and the production of race and ethnicity during different types of research interactions. Our way of doing memory work consisted of each of us separately writing down our memories ${ }^{1}$ of particular instances when we have been conducting research, and our own or our research participants' race or ethnicity has been brought to the fore during the interaction,

\footnotetext{
${ }^{1}$ We recognise, of course, that 'memories' themselves are not stable repositories from which we are able to 'pluck out' 'the truth'. Rather, we share Ahmed's view that: "writing of the self in the form of an individuated memory may serve to de-stabilize the boundary between the subject and its others" (1997:153). She also notes that the performative act of remembering is "critical, affirmative and selective, (and) places boundaries and edges around the story, giving it its seeming internal coherence"; and the story that is remembered and retold "entails its own elisions, its own figuration, its own forgettings" (1997:162, emphasis added). We argue that this is one of the places where the added value of comparative memory work is most salient, as our joint discussions of each our memories contributed to questioning the boundaries and edges we each placed around our stories.
} 
even though neither race nor ethnicity was the topic of discussion. We then met face to face on two separate occasions to discuss what we thought was 'going on' during these interactions, and how we might analyse them. The article is based on these face to face and remote dialogues; after a brief discussion of the relevant theoretical framing of the main themes in the article (race and ethnicity), the textual layout of the article emphasises the individuality of our respective research experiences, but analysed in dialogue with each other.

\section{Race and ethnicity in research encounters ${ }^{2}$}

Although ethnicity, race and processes of racialisation are often overlooked in analyses of research encounters ${ }^{3}$, they have profound impacts on field relations, as well as on research outcomes. The analysis of our research experiences is informed by Gunaratnam's postcolonial approach to researching race and ethnicity. She views research as a discursive practice, which means that research is a part of social and historical relations, and it is productive rather than simply reflective of what we research (Gunaratnam 2003: 7). Conceiving of research on race and ethnicity as a discursive practice presents the researcher with an analytic opportunity to interrogate their own "current understandings, interests and research practices" (Gunaratnam, 2003: 8). This type of analytic interrogation has three main benefits: a) it challenges the "view of research as an unlocated and transparent reflection of some pre-existing, stable 'reality'"; b) it adds complexity to the analysis because the research becomes a process of understanding "knowledge as an emergent property of the interactions between and among differently constituted and located individuals, who include the researcher"; and c) knowledge claims based on the research will be situated relative to social and historical relations (Gunaratnam, 2003: 8). It is the second of these benefits that this paper focuses on: we discuss how race and ethnicity are produced during research interactions, highlighting the particular themes or discourses that framed the expressions of racialised and ethnic identifications (and disidentifications) during the interactions.

In this article, we understand race and ethnicity as: "Concepts, ideas referring to social and political (but not biological) distinctions made between people" (Knowles, 2003: 18). As such, they are both social constructs that are not intrinsically meaningful or important, but have real and material effects because they are "linked to relations of power and processes of struggle" (Frankenberg, 1993: 11). Both terms have "real, though changing effects in the world and a real, tangible, and complex impact on individuals' sense of self, experiences, and life chances" (Frankenberg, 1993: 11). Race and ethnicity are, of course, analytically distinct from each other and differently constructed; however, they often operate together and tend to be subsumed into each other. The emergence of the category of race has been traced to the scientific racism that marked the nineteenth and early twentieth centuries (McClintock, 1995; Rattansi, 1995; Modood, Berthoud and Nazroo, 2002; St Louis, 2005). Human beings were categorised in a hierarchy in which non-Europeans (non-whites) were viewed as being from distinct, sometimes sub-human, races, sharing a common stock and phenotype (see Gilman, 1992). Hence the inextricable link between race and biology; as Alcoff suggests, race is "marked on the body through learned perceptual practices of visual categorization, with significant sociological and political effects as well as a psychological impact on self-formation" (Alcoff, 2007). However, in addition to being closely tied to perceived biological differences between human beings, race has historically also

\footnotetext{
${ }^{2}$ Our discussion in this section is mainly based on British and Anglo-American literature; Scandinavian literature in this field has slowly been increasing over the last twenty years or so see for example Hylland Eriksen, 1993; Gullestad, 2004 and Keskinen et al., 2009.

${ }^{3}$ Some exceptions to this include Phoenix, 1994; Bhopal 2001; Egharevba 2001 and Carter 2004.
} 
been closely linked to conceptions of national and cultural uniqueness (see Brooks Higginbotham, 1992; Brah, 1994; Hall, 2000).

In contrast, ethnicity is a term that derives from the Greek term ethnos, which originally meant a heathen or pagan; thus, from the outset, a reference to ethnicity signified 'the Other' (Brah, 1994). Alcoff views ethnicity as a term that signifies "a group's relationship to historical experiences and cultural practices, and they are indicated more by practices than by physical appearance" (Alcoff, 2007). Thus, race and ethnicity are generally distinguished from each other by linking the former to biology, and the latter to culture, religion and kinship. However, this 'neat split' has increasingly been challenged and re-thought, as the complexities of both categories and their relationship to each other have been exposed both theoretically and empirically (Gunaratnam, 2003:4). This can be seen, firstly, by noting that invoking the notions of shared origin or 'kith and kin', references to ethnicity can also be used in ways that depend on quasi-biological conceptions (Rattansi, 1995:258). Secondly, people are categorised through processes of racialization on the basis of their race or ethnicity, which can lead to discrimination or attacks, inter alia; therefore, in many instances, ethnicity is racialised (Modood, Berthoud \& Nazroo, 2002:420). Thirdly, people can be racialized in different ways within either of the black or white racial categories, as exemplified in the racialization of Irish people in the UK (see Hickman and Walter, 1997), and in the contestations between American citizens of Caribbean descent and African-American citizens over who can legitimately claim to be 'African American' (see St Louis, 2005). Fourthly, ethnicity can take many forms: it can be signified through language, food, clothing, a person's general appearance or the apparent colour of their skin. Whatever the form that ethnicity takes, it is always context specific: in the example given by Modood, Berthoud and Nazroo, ethnic conflicts in Belgium, Bosnia Herzegovina, Northern Ireland or Rwanda were not based on skin colour differences (2002:422). Finally, both race and ethnicity can simultaneously be self-assigned by groups and individuals, or internally/externally ascribed to groups and individuals by (Modood, Berthoud and Nazroo, 2002).

The research interactions we discuss here bring to the fore "the complex overlapping and crosscutting of boundaries that characterises the formation of ethnic and racialised identities" (Rattansi, 1995:258). The interactions we discuss specifically highlight the ways in which ethnicity is used in everyday and research interactions (though we focus on the latter here), both implicitly and explicitly, to refer to processes or instances of racialization. Individuals and collectivities draw on a wide range of cultural repertoires to construct, express or perform raced or ethnic identities, resulting in a 'slippery slope' relationship between the two categories, which are, therefore, easily subsumed into each other in practice. What we discuss below shows some of this 'slipperiness', and the ease with which race and ethnicity can emerge and 'masquerade' as each other in research interactions. In so doing, we aim, as Gunaratnam suggests, "to address and to account for the specific relationships between our analytic categories and subjective, social and material relations" (Gunaratnam, 2003: 5, emphasis in the original).

In what follows, we describe and analyse our research experiences based on the on-going dialogue we have had with each other. Using memory work as an analytic tool alerts us to how race and ethnicity are 'always already' (Lewis, 2006) present in research encounters, although, as our analysis will show, we can never in advance predict how, where, by whom or from which perspective either category will be produced in any given interaction. We compare and contrast our respective memories and experiences in light of our different (re)positionings. This 
is done in relation to three key themes, which emerged during our discussions about how the production of race and ethnicity was framed during our interactions. The themes are: constructing difference, power imbalances and disorientation.

\section{Constructing Difference: Between Researcher and Researched}

madeleine: During the interviews I conducted with school pupils in 'inner city' London for my doctoral research, I asked pupils to answer this question: "Which place are you a citizen of?" One pupil responded by saying: "I am Dutch, but I was born in Somalia and now I live in England. There are people like you in my country...like... they are like...black. I am a white Somali".

In this exchange race is produced within a black/white dualism. However, what is interesting in the interaction is the fact that my interviewee's whiteness is geographically located outside of the west/non-western or global north/south divides that habitually underpins the black/white binary. Rather, the category of 'white Somali'4 (a racialised ethnicity) evoked by my interviewee highlights Frankenberg's point that "whiteness as a site of privilege is not absolute but rather crosscut by a range of other axes of relative advantage and subordination; these do not erase or render irrelevant race privilege, but rather inflect or modify it" (Frankenberg, 2001: 76). It also exemplifies what Twine and Gallagher have argued is a 'third wave' perspective on whiteness studies (originating in the United States), which "rejects the implicit assumption that whiteness is only an unconditional, universal and equally experienced location of privilege and power" (Twine and Gallagher, 2008: 7). As such, they also note that as a source of power and privilege, Whiteness 'travels' between different geographical locations, including between western countries and erstwhile colonies (Twine and Gallagher, 2008: 10). This travelling is made evident in the interviewee's remark: she tells me that she is Dutch (she is a citizen of the Netherlands), but was born in Somalia and was living in England at the time of the interview. In relation to me, and people 'like me' in 'her country' (one can assume she was referring to Somalia), she identified as white. This is despite the fact that she would be classified as a nonwhite 'ethnic minority' in both the UK and the Netherlands5. Identifying as a 'white Somali' meant she could distance herself from other (black) ethnic minorities in the European countries she has lived in (and perhaps also in a Somali context). In effect, this was a "strategic deployment of whiteness" (Twine and Gallagher, 2008: 13), by someone who, in the UK or Dutch context, would ordinarily be located at the racialised ethnic margins of the nation. It could also be read as a power move, to shift the imbalance of power between me (an adult researcher) and the interviewee (a school pupil). By pointing out that I am black and she is white, the interviewee catapulted us and our relationship to each other beyond the classroom and the interview into the wider world, which is riddled by racialised relationships of dominance and inferiority.

The interviewee could certainly have 'passed' as someone from the near or middle east, countries such as Turkey, Lebanon or Syria, who in turn could 'pass' for, or be considered as

\footnotetext{
${ }^{4}$ It should be noted that there are Somali people who are said to be of Portuguese descent, so it could be that this pupils was from one of these groups, which could explain why she selfidentified as white (see Luling, 2006).

${ }^{5}$ In the Netherlands, she would be classified as an 'allochtoon' (allochtonous in English). This is a Dutch word, which emerged as a racial-ethnic label in the mid- 1990s in the Netherlands, to mean the opposite of 'autochtoon', who are those that are 'indigenous, native, authentic' Dutch people (Essed and Trienekens, 2008: 57).
} 
white, at least in relation to someone of a darker skinned complexion. As we noted earlier, there are further racialised hierarchies within the stratified racial categories of black and white. The pupil had a fair-skinned complexion; I could not see the colour or texture of her hair because she wore a headscarf (hijab). Racial passing has been theorised in academic writing, and addressed in literature, generally from North American perspectives (see Gates, 1997 and Larsen, 1929, Roth, 2000, respectively). It is the phenomenon of people with lighter skinned complexions choosing to present themselves as white, or being mistaken as such. In my interaction with this pupil, I was equally surprised by her telling me that she was Somali (from her looks and her headscarf, I assumed she was from a near or Middle Eastern country), as her identifying specifically as a white Somali (I had never encountered anyone who identified as such before). The pupil could certainly have been aware of the assumptions people made about her based just on her looks, assumptions I was also guilty of making, although I did not communicate them to her. So she found a way of asserting her identity, even though this was not directly what I had asked her about. Her response showed clearly the complex links between racialised ethnic identification, whether self-imposed or ascribed, and a sense of citizenship/belonging. The pupil claimed formal Dutch citizenship, and also claimed England and Somalia, her place of residence and birth, respectively. I theorised this as a claim for a form of diasporic citizenship ${ }^{6}$, based on the results of the study that the pupil was part of. Based on the earlier interviews I had conducted with pupils at this school, I had come to expect that many of them would talk about a multi-faceted understanding of citizenship. However, I was taken aback by this particular pupil's construction of a racialised ethnic difference between herself and me during our interaction.

Helene: I did my PhD research in Australia and New Zealand. The project was about experiences relating to the inclusion of Indigenous interests in politics in both countries. I had an appointment for an interview with the head of an Aboriginal Education Department in Australia. Below is a short research diary entry I made about the interview, followed by an extract from the interview.

He appeared to be a very busy man; he emerged from one meeting and went straight into the meeting with me (in a very flashy air conditioned office, with lots of Aboriginal art and the Aboriginal flag next to an Australian one at the entrance of his section of the building). He repeatedly looked at his watch while talking to me, which is why I kept it short [...] He was very correct both in speech and appearance, spoke very fast and I got the feeling that in some ways he was delivering the 'official' pre-prepared speech.

"I think one of the things we have to be clear about here is that I am an Aboriginal person myself - if you want to learn about my culture, I'll take you out in the bush and I will show you what my culture is all about. [...] But if Aboriginal kids are going to learn about Western culture, which they must do, they have to do it in the same environment as non-Aboriginal kids are doing it,

\footnotetext{
6 The study was my doctoral thesis in sociology (2008), entitled "'The Citizen Thingy": Becoming Diaspora Citizens in Inner City London and in a Paris banlieue'. It was a qualitative study of perceptions and experiences of 'citizenship' amongst minoritised young people living and attending school in marginalised parts of suburban Paris and inner city London. My thesis builds on and expanded understandings of the relationship between diaspora and citizenship in these two metropolitan centres.
} 
and that is in the schooling environment. What we have to do, is to make that schooling environment as inclusive of Aboriginal kids as possible. [...] schooling in Western Australia for Aboriginal people started in 1965, and was compulsory. So it is really, we've only been doing it for 40 odd years. [...] So we are looking at two generations here, the initial generation - my mum for example [...] she is part of the Stolen Generation, so that went through missions, so their concept of schooling is very different from my concept of schooling that I have had with my daughter. Unfortunately, people at my age, between 45 and 50, have had a range of experiences with school, most of which were not desirable, were not good experiences".

Here Aboriginality is constructed in a number of ways. Structurally (my respondent is head of the Aboriginal Education Department); spatially (I have to enter a specific wing in a big government building, and this section of the building has different types of decoration from the rest, as does his office); and in terms of a personal narrative (my interviewee tells me that he is Aboriginal, and mentions that his mother is part of the 'Stolen Generation' $)^{7}$. I remember this personal narrative of my respondent's own Aboriginality very vividly from the interview situation because I was so surprised by it at the time: it seemed unnecessary and irrelevant (to me) for the purpose of the interview, which I had announced in advance as being about "the extent to which the educational systems helps shape citizens who feel their voice and opinion would matter". The construction of ethnic difference in this interview, between the interviewee and me, was interlinked with constructions of other types of difference that were neither related to race nor ethnicity. First of all, the interviewee indirectly underlined our age difference. Secondly, immediately after he made the statement above, the interviewee 'turned the tables on me', and asked about when compulsory schooling started in my home country. The interviewee's response can be read as him underlining the racialised and ethnic differences between us (he explicitly told me about his Aboriginality), and as challenging the power positions in the interview situation (when he took on the role of interviewer by asking me questions) 8 .

I had arranged this research encounter because of the structural construction of Aboriginality within the Australian State's Administration: the Education Department had a separate Aboriginal Education Department. Aboriginality was not part of the construction of the mainstream - it was literally dealt with in a separate wing of this building. However, I was unprepared for the respondent's personalised expressions of Aboriginality. According to Gunaratnam, interrogating race and ethnicity as a discursive practice has the advantage of adding complexity to research analysis, since it becomes necessary to consider, amongst other things, the location of individuals (respondents and researchers alike). She argues that it is valuable to examine the spatial dimensions of difference in research encounters (Gunratnam, 2003: 157). Making Aboriginality so symbolically present in my interviewee's office space could

\footnotetext{
${ }^{7}$ Meaning that she was forcefully removed from her own Aboriginal mother due to being 'halfcaste', and needing to be 'rescued' from Aboriginal culture, since being 'half white' meant that she had the potential to be a 'white person' - a job the mission stations were entrusted with (see McCarthy 2000, Day 2003, and Read 2006).

${ }^{8}$ In fact, this was a common occurrence in this study, which I undertook whilst in my mid-20s and far away from my country of origin, more often than not interviewing high ranking senior public officials. In several of these interviews, respondents also started quizzing me about Denmark's relations to its former colony Greenland.
} 
be read as a legitimising strategy, or one of authenticity, used to assert his own identity, and the identity of the communities that he represented, accentuating a racialised specificity. This specificity was further emphasised by his drawing in of the wider geographic context of the interview, which clearly positioned me as an ethnic foreigner, who was additionally racially different from him.

In both our memories, the wider geography of global power relations where unexpectedly drawn into the space of the research setting. Race and ethnicity were produced in these encounters when our interlocutors highlighted the racialised ethnic difference between themselves and each of us. In both cases we feel that we did not explicitly invite these productions of difference, and we were both, in fact, rather surprised by their occurrence. Race and ethnicity were produced and deployed in ways that neither of us could have predicted: madeleine did not foresee that the pupil in front of her would self-identify as 'white', nor did Helene foresee that a public official interviewed because of his administrative responsibilities and experiences would 'confess' his ethnicity during the interview. However, such seemingly 'unexpected' deployments of racial and ethnic categorisations in research encounters are useful and important to dwell on, because they attest to the ways in which, despite our personal understanding of race and ethnicity as social constructions, they continue to be filled with 'common sense' meanings and attributed with high levels of symbolic and material significance in everyday life. As St Louis has argued: “...an awareness of the analytical exhaustion of race has not weakened the energy of the affective investments it enthuses" (St Louis, 2005: 361); we suggest that the same applies to (racialised) ethnicity.

\section{Power Imbalances}

madeleine: I was in Guinea, visiting a newly formed organisation working on the eradication of the practice of female genital cutting/mutilation (FGC/FGM) amongst refugee communities who had fled the war in Sierra Leone during the 1990s. The organisation I worked for in London had funded some of the work done by the organisation in Guinea; I was there to assess and evaluate the work. During the second day of my visit, the staff gave individual presentations of their area of work. One staff member was an older man, a teacher, who was responsible for the organisation's literacy programme. After the presentations, I chatted informally with members of staff. We were talking about the work that NGOs do in African countries, and the fact that African countries needed this type of far-reaching civil society involvement. The older male teacher said to me: "You know we also have good people here, Africans, men like me who are teachers with many years of experience. All of the know-how is not only in Europe. I have a degree from university you know. What about you?" I told him that I had also been to university, and that I was half-way through my PhD. He exclaimed his shock and surprise that someone as young as me was "almost a doctor!" He said that from then on, he would call me 'Madame', rather than use my first name.

My interlocutor brings to light the otherwise unspoken power/knowledge nexus, with which my position as 'an expert from Europe' representing a donor organisation was imbued. His challenge was gendered and linked to ethnicity ("Africans, men like me"), and he seemed to suggest he (or other men like him) could have been more qualified to do the type of work I, a young woman who may not even have a university education, was doing. My interlocutor's response brought to the surface real and perceived discursive and material imbalances of power between Europe/Europeans/diaspora Africans in Europe and Africa/Africans in Africa. However, the fact that I was in the process of doing doctoral studies caused him to re-position me as 'powerful', through his insistence that my level of academic study meant that he could 
not treat me as his equal by using my first name. This is a significant turn-around in a West African context where hierarchies are central to social life. It was no small thing for an older, educated man to deign it appropriate to refer to me, a younger woman, as 'Madame'.

Helene: The consent form that I used before starting interviews in a study of immigrant women's associations in Denmark, described my study as "an investigation of participation by Muslim and other immigrant women in various types of organisational work and (local) politics". One respondent I contacted due to her prominent position in an Iranian women's organisation reacted forcefully to this formulation in the earliest stages of the interview, saying: "Is that a truth that Iran is an Islamic country? But you cannot single out all individuals and then say because you are 'from Iran' you are 'Muslim' [...] But it is something about Denmark, you see things from outside right? Then you see Muslim women. You could formulate it as 'women from Muslim countries'". I agreed with her that her suggestion for a different formulation was better.

During another research encounter within the same project, a woman of Somali origin told me right at the beginning of the interview that she had participated in numerous long interviews with various researchers, who never got back to her with feedback or told her about the findings from their work. As she pointed out, these people received a salary for conducting the interviews, while she was simply expected to volunteer her time with researchers. She added: "It would be easier to get the ideas from the people if you pay them a little bit [...]. But I don't make any conditions".

Both of these examples show that the respondents wanted me to know that they were aware of the imbalance of power in the interview situation. In the first example, as researcher, I was the one who defined the terms of the interview and had the power to 'label' interviewees (see Jørgensen, this volume). In the second, I was the only one getting any type of benefit (as the respondent says, her 'ideas') from the interview, and potentially not giving anything back to the interviewee, who does not or cannot "make any conditions". In both examples, the interviewees show how the power imbalance in the interview setting is directly linked to the low positioning of racialised 'immigrants' in Denmark. However, the picture is complicated by the fact that neither of the two respondents were 'typical immigrants': both were researchers themselves, working respectively for a Danish university, and on an EU contract for a project on combating female genital mutilation among the Somali Diaspora. This is not to claim any ontological or experiential similarity between my position as an interviewer and the position of the respondents. Rather, it is to say that because these respondents were positioned as powerful in some ways, they were able to challenge my taken-for-granted and unarticulated position of power, and question the authenticity of my re-presentations of their 'ideas' in my research analysis.

This leaves open the question of whether I should simply have refrained from undertaking these interviews. In her paper 'The Problem of Speaking for Others', Alcoff (1991-92) discusses the intricacies of subject positions and power relations in acts of speaking for others as well as for one self (see also Faber, this volume). Although highly attentive to the risk of repressing or presuming authenticity of subject positions when speaking for others, Alcoff concludes that retreat from re-presentation is not a satisfactory solution either. Following Spivak (1988), she concludes that the best option is to 'speak to', rather than 'speak for' or 'listen to', although both options retain an essentialising approach to the subject positions of the less powerful. The notion of 'speaking to' allows for the possibility that the interlocutor will produce a 'counter 
sentence'. It is only through addressing others, including racialised others that we create opportunities for counter sentences to appear. Järvinen (2005) discusses how the researcher invites the interviewee to speak from specific subject positions, and how identities are thus 'offered' in interview situations (see also Jensen, this volume).

By revisiting memories of previous research encounters, we can look for instances when, as interviewers, we have been 'offered' specific identities by our respondents, and consider how the identities offered in these cases may have altered the terms of engagement between ourselves and our interlocutors. As our examples above illustrate, we are sometimes offered specific positions by our respondents and we may be 'spoken to' or addressed in specific ways. Here, our interactions can be seen as instances of 'hailing' or 'interpellation' (Althusser 1971) ${ }^{9}$ of us in response to our own initial hailing of our interlocutors. Hall has argued that identification "means that a person is 'called' in a certain way, interpolated in a certain way: 'you, this time, in this place, for this purpose...'" (Hall, 1997: 292). In research interactions, both parties 'speak to' each other in particular ways, although the researcher retains the ultimate power both by initiating the interaction and by 'speaking for' the researched when publishing results. What is perhaps most important for researchers is to remain aware that research interactions are bound in time and space ("you, this time, in this place, for this purpose"), although the results of the interactions are by no means predictable. Revisiting (new time and new place) old research data to investigate processes of racialisation or positioning in relation to ethnicity in research encounters (new purpose), is a useful way of investigating the effects of hailing. By expressly searching for memories in which we have been openly hailed in ways that emphasised specific aspects of our ascribed identities, it is easier for us to recognise how we also hailed our respondents. Although the opportunity for a real dialogue with our respondents about the effects of hailing has long passed (we are dealing with memories), it is still possible to develop a dialogue with other researchers ex post about hailing and the (sometimes racialised or ethnicity-linked) power relations implicit in such practices.

\section{A Sense of Disorientation}

madeleine: Part of the empirical research for my doctoral thesis was conducted in a secondary school, in a suburb (banlieue) south-east of Paris. After a period of participant observation, I interviewed a number of students, who were 'volunteered' for the interview by the classroom teacher. One of my interviewees was one of the very few white French girls in the classroom. Prior to being interviewed, during break-time chats, this pupil had self-identified as an 'anglophile', and she was eager to speak to me about England. During the interview, we had the following exchange:

m: "What does being a French citizen mean to you?"

L: “Well, it means...erm...yeah, freedom, yeah freedom and equality, yeah... I'm free to go where ever I want, to do what I want..."

m: "Are what re the other advantages to being a French citizen?"

L: "Speaking a beautiful language, living in a beautiful country."

m: "Are there any disadvantages?"

L: "Disadvantages...I'd say.....hmm...I'd say having to have foreigners who...erm...I'm not racist, right, but sometimes there are foreigners

\footnotetext{
${ }^{9}$ In Althusser's understanding, 'hailing' refers to how ideologies position subjects in certain ways. However, as we do not share Althusser's structuralist starting point, we focus instead on relational/inter-personal understandings of the concept of hailing.
} 
who...who...even French people, who don't respect the laws of France...I don't

like that at all, not one bit."

During this interview, I was completely caught off guard and felt somewhat disorientated by the pupil's response to my question about what she considered to be the disadvantages to being a citizen of France. I did not expect to be confronted with such views from such a young person (she was 14 years old), and particularly since I was 'a foreigner'. My disorientation stemmed from the fact that I struggled to maintain my researcher/listener stance as the pupil spoke, without challenging what she said to me. There was presumably also some discomfort felt by the pupil as she spoke, because even though she managed to tell me her opinion, her statement was punctuated by hesitation, and she paused frequently between her words. In order to express her thoughts on the subject I raised, my interviewee had to negotiate the 'elephant in the room': the fact that I was or could be construed as one of the 'foreigners' that she referred to. To this end, she qualified her statement by saying: "I am not racist, right..." It was perhaps also 'easier' for her to tell me her thoughts because I was a 'different type' of foreigner: I was only in France temporarily, and she felt some affinity with me because of my Britishness and her own enthusiasm for all things Anglophone.

Helene: My work on my PhD thesis took me to a university in New Zealand, where I spent two months as a visiting doctoral fellow in a close-knit community of researchers. We all shared the ups and downs of our research experiences with each other. One day I returned to office after an interview that I thought was particularly successful, with a group of five people. Before the interview started, they had suggested that everyone introduce themselves, and I was more than happy to oblige. What I had not foreseen, was that for three of the five respondents, an introduction included announcing their whakapapa (their ancestry). Back at the office, I bumped into a Pakeha (white) colleague who asked me how the interview had gone. I replied "fine" and laughingly added that, of course, I would hardly understand anything from the first 10 minutes or so of the interview recording, as most of it was in Maori. She replied: "You realise they did that to intimidate you, don't you?"

I was completely thrown and disorientated by this remark. It did not relate in any way to how I had experienced the interview situation. Rather, here is a research diary entry I made on the day after the interview:

Tuesday June 22 2004 - post interview reflections: "I have thought quite a lot about what impression the Maori incantations made on me yesterday at the meeting at NZEI [New Zealand Education Institute] - mainly, I think, because when I told ['Georgina'] about it, she suggested that it was part of a strategy to intimidate me. But I didn't feel intimidated - awed rather. This morning when I was walking to the bus stop I was thinking about it, and it struck me that it rather felt like when I was a child and listened to my grandfather's Bible readings before meals. I remember that feeling of not really understanding what was going on, but knowing that it was important and you had to be quiet, and that it meant that somehow we were not alone when eating the meal."

My sense of disorientation was produced in the interaction with my colleague, who implied that I ought to have been intimidated or disorientated by my research encounter. It was this interlocutor, marked by racial 'sameness' with me, who produced the sense of disorientation, rather than my Maori interlocutors. Ahmed argues that "whiteness is an orientation that puts 
certain things within reach [...] not just physical objects, but also styles, capacities, aspirations, techniques, habits. Race becomes, in this model, a question of what is within reach, what is available to perceive and to do 'things' with" (2007: 154). My colleague suggested that my interviewees were trying to intimidate me by enacting the ritual of whakapapa, implying that they might have felt the ritual was beyond my reach or outside of my understanding due to my whiteness/foreignness as a Danish person in New Zealand. However, this was not how I experienced the research encounter, neither at the time it occurred, nor when I reflected on it afterwards. I felt disoriented by my colleague's interpretation of the encounter, which left me wondering whether she was implying that my Danishness was a handicap, especially when it came to interviewing Maori people. It felt more like my colleague was challenging my ability to engage with Maori people, than (as she suggested) that the Maori interviewees had challenged me through their enactment of whakapapa.

Juxtaposing our respective research experiences highlights their differences as well as their similarities. In Helene's case, her foreignness is highlighted in interactions with both Maori and non-Maori New Zealanders, although only the second interaction leaves her feeling disoriented. In madeleine's case, she is disoriented by her interviewees paradoxical, hesitating reference to 'foreigners' during the interview, which simultaneously situated her (madeleine) both inside and somehow also outside of the category of 'foreigner' (on the spuriousness of categorisations, see Jørgensen, this issue). Whiteness was not explicitly named in either scenarios, but it was the unmarked 'elephant in the room', that framed and accentuated the 'foreignness' alluded to or remarked upon by our interlocutors. The examples also show how racialised difference can be invoked by people positioned as racially 'similar' to oneself, as well as by those positioned as 'different'. Like Baldwin (1984), hooks (1990) and Frankenberg (1993), we view whiteness as a constructed identity that can be contested as well as deconstructed, and we would argue that "the epistemological stickiness and ontological wiggling immanent in whiteness" (Hill, cited in Ware, 2002: 29) is an obstacle best overcome in dialogue with others - for example in dialogue with other colleagues about the effects and affects of racialisation in interview situations.

In Out of Whiteness, Back suggests that a sense of disorientation could be viewed as an interpretive position from which to conduct research (Back, 2002: 59). In Helene's example, her disorientation led her to reject her colleague's interpretation that her whiteness/foreignness could be perceived as disqualifying her from conducting research on Maori lived experiences. In madeleine's example, the disorientation caused by the pupil's opinion called for a reassessment of how she was perceived, and, therefore, interacted with, as a visitor from Britain. The 'unexpectedness' that characterised these interactions is what triggered a closer reading of the ways in which race and ethnicity were produced. Taking disorientation as an interpretive stance is also akin to the methodological approach advocated by Lather, who argues that researchers should get "lost" and approach their data with "rigorous confusion" (Lather, 2007: 137). We have found engaging in comparative post-research memory work in dialogue with another researcher who is differently racialised from ourselves to be a useful approach to 'getting lost' in our research. Our discussions about how to interpret the memories and whether or how our experiences differed or were similar contributed to the rigour of the exercise. In general, Lather advocates 'member check', and she speaks about: "Inviting the women in [their] study to see themselves being studied" (2007: 42), something she refers to as "looking-at-beinglooked-at-ness". Lather considers this a useful exercise in leaving both the researcher and reader open to scrutiny about what we think we know. We suggest that a 'colleague check' is an equally useful exercise. In Getting Lost, Lather asks "what might feminist knowledge projects look like that work within and against identity categories, visibility politics, and the romance of 
voice?" (2007: 36). We suggest that one version of such feminist knowledge projects could include engaging in comparative and contrastive memory work, as we have done here.

\section{Concluding Discussion}

The research experiences in this article show that the production of race, ethnicity or racialised ethnicity cannot necessarily be predicted in advance of research encounters. We cannot tell in advance the situations in which either or both categories will be produced and given meaning, what will trigger it, or who will voice it. In addition, despite being positioned as 'racially and ethnically different' from each other, we have memories and research experiences that show many commonalities. Despite our demonstration in this article of how racialised and ethnic identities may be produced through research interactions, we also wish to emphasise that those identities are not 'natural' or fixed; they are socially constructed and produced/reproduced in a constant negotiation in interactions with other people. This, however, does not mean that they are without impact. Alcoff reminds us that: "Race [or ethnicity] may be a social construction without biological validity, yet it is real and powerful enough to alter the fundamental shape of all our lives" (Alcoff, 2006: 207).

Focusing on the ways in which race and ethnicity are produced in research interactions, helps us to remain mindful of the constructed nature of race and ethnicity, both inside and outside of research encounters. We have found it useful to juxtapose our memories of research experiences in this exercise, in line with the feminist calls for careful, relevant and rigorous reflexivity in research (see for example, Gunaratnam, 2003). Feminist memory work is an approach to reflexivity which requires us to not leave personal experiences and feelings 'at the door', but to bring them into the room of the research, as part of the arsenal of tools that can help researchers to avoid essentialisation. Apart from the question of how we are met by our research field, there is also the question of how we meet the field. A central challenge for any social science researcher is to resist the impulse to render 'exotic' or 'Other' (Brah and Phoenix 2004: 79) those they are researching. The question is of course, how to do that? Assuming similarity or even likeness can be potentially just as violent as representations of, or a focus on, difference. We would suggest that it is possible, and even fruitful, to direct the impulse for rendering 'exotic' at oneself - and, following Lather, to get a little lost. In recalling research situations in which we have felt (or been made to feel) our own 'difference' or 'sameness', or when the power imbalance in research interactions have been highlighted, or we have simply felt disorientated, an opportunity is created for destabilising categories and categorisations which may otherwise go unquestioned.

Frosh, Phoenix and Pattman suggest exerting 'energy' in the encounter between researcher and research subjects (Frosh et al, 2003: 49). They also state that: "Subject positions are coercive and complex" (Frosh et al, 2003: 52), but if we invest energy in our encounters with others, we may be able to challenge the coerciveness of those positions and expose their contours from within. We need to engage and invest energy in feeling the presence of race or ethnicity in our research encounters. It is our contention that using memory work in the analysis of research experiences is one way to exert such energy. The type of dialogic comparative memory work we have undertaken in writing this article seems particularly fruitful to us, because it opens up the issue of how race and ethnicity are produced in research interactions in a much more concrete way, precisely because we have debated the issue across our respective racial and ethnic positions. In particular, we have sought to use our different positionalities to help each other with the necessary "ontological wiggling" (Hill, cited in Ware, 2002: 29), but also deliberatedly attempted to get lost in the "headwork" and "textwork" (Lather 2007) of our memories, by 
engaging in a prolonged conversation about them. Put simply, we contend that we need to talk about what race (and ethnicity) feels like in order to appreciate the complexities of their production in research encounters.

\section{References}

Ahmed, S. (1997), "It's a sun-tan, isn't it?" Autobiography as an identificatory practice, in H.S. Mirza (ed.) Black British Feminism: A Reader. London: Routledge.

Ahmed, S. (2007), The Phenomenology of Whiteness, Feminist Theory 8(2): 149-168.

Alcoff, L. (1988), Cultural Feminism versus Post-Structuralism: The Identity Crisis in Feminist Theory', Signs 13(3): 405-436.

Alcoff, L. (1991-92), The Problem of Speaking for Others, http://www.alcoff.com/content/speaothers.html last viewed on January $25^{\text {th }} 2012$

Alcoff, L. (2006), The Whiteness Question, pp. 205-224 in Visible Identities, Race, Gender and the Self, Oxford Scolarship Online

Alcoff, L. (2007), Comparative Race, Comparative Racisms, http://www.alcoff.com/content/comprace.html last viewed on January $23^{\text {rd }} 2012$

Althusser, L. (1971), Lenin and philosophy and other essays. London: New Left Books.

Back, L. (2002), Guess Who's Coming to Dinner? The Political Morality of Investigating Whiteness in the Grey Zone, pp. 33-59 in Back, L and Ware, V. (eds.) (2002), Out of Whiteness: Color, Politics and Culture, Chicago: University of Chicago Press.

Baldwin, J. (1984), On Being White...And Other Lies, in D. Roediger (ed.) Black on White. New York: Schocken Books.

Berg, A-J. (2008), Silence and Articulation - Whiteness, Racialization and Feminist Memory Work, NORA - Nordic Journal of Feminist Gender Research 16(4):213-227.

Bhopal, (2001), Researching South Asian Women: Issues and sameness and difference in the research process, Journal of Gender Studies, 10(3):279-286.

Brah, A. (1994), Time, Place and Others: Discourses of Race, Nation and Ethnicity, Sociology 28(3):805-813.

Brah, A. and Phoenix, A. (2004), Ain't I A Woman? Revisiting Intersectionality, Journal of International Women's Studies 5(3):75-86.

Brooks Higginbotham, E. (1992) African-American Women's History and the Metalanguage of Race, Signs 17(2):251-274.

Carter, J. (2004), Research note: reflections on interviewing across the ethnic divide, International Journal of Social Research Methodology 7(4): 345-353. 
Day, D. (2003), Australiens Historie, Roskilde: Roskilde Universitetsforlag, translation by Lars Jensen

Egharevba, I. (2001), Researching an-'other' minority ethnic community: Reflections of a black female researcher on the intersections of race, gender and other power positions on the research process, International Journal of Social Research Methodology 4(3):225-241.

Essed, P. and Trienekens, S. (2008), Who wants to feel white? Race, Dutch culture and contested identities, Ethnic and Racial Studies 31(1):52-72.

Frankenberg, R. (1993), White Women, Race Matters: The Social Construction of Whiteness. Minneapolis: University of Minnesota Press.

Frankenberg, R. (2001), The mirage of an unmarked whiteness, in B.B. Rasmussen, E. Klinenberg, I.J. Nexica and M. Wray (eds.) The making and unmaking of whiteness. Minneapolis, M.N.: University of Minneapolis Press.

Frosh, S., Phoenix, A. and Pattman, R. (2003), Taking a stand: Using psychoanalysis to explore the positioning of subjects in discourse, British Journal of Social Psychology 42:39-53.

Gilman, S. (1992), Black Bodies, White Bodies: Toward an Iconography of Female Sexuality in Late Nineteenth Century Art, Medicine and Literature, in J. Donald and A. Rattansi (eds.) 'Race', Culture and Difference. London: Sage.

Gates, H.L. (1997) Thirteen ways of Looking at a Black Man. New York: Random House.

Gullestad, M. (2004), Blind slaves of our prejudices: Debating 'culture' and 'race' in Norway, Ethnos: Journal of Anthropology 69(2):177-203.

Gunaratnam, Y. (2003), Researching 'Race' and Ethnicity: Methods, Knowledge and Power. London: Sage.

Hall, S. (2000), Conclusion: The multi-cultural question, in B. Hesse (ed.) Un/Settled Multiculturalisms: Diasporas, Entanglements, Transruptions. London: Zed Books.

Hall, S. (1997), Subjects in History: making Diasporic Identities, in W. Lubiano (ed.) The House that Race Built: Black Americans, US Terrain. New York: Pantheon Books.

Haug, F. \& others (1987), Female Sexualization: A Collective Work of Memory. London: Verso.

Hickman, M. and Walter, B. (1997), Discrimination and the Irish Community in Britain. London: Commission for Racial Equality.

hooks, b. (1990), Yearning: Race, gender and cultural politics. Boston: South End Press.

Hylland Eriksen, T. (1993), Ethnicity and Nationalism: Anthropological Perspectives. London, Boulder, COL: Pluto Press.

Jansson, M., Wendt, M. and Åse, C. (2008), Memory Work Reconsidered, NORA - Nordic Journal of Feminist and Gender Research, 16(4):228-240. 
Järvinen, M. (2005). Interview i en interaktionistisk begrebsramme. In M. Järvinen \& N. MikMeyer (Eds.), Kvalitative metoder $i$ et interaktionistisk perspektiv. København: Hans Reitzels Forlag.

kennedy-macfoy, m.(2008), "The Citizen Thingy": Becoming Diaspora Citizens in Inner City London and in a Paris banlieue. Un-published doctoral thesis, Goldsmiths, University of London, Department of Sociology

Keskinen, S., Tuori, S., Irni, S. and Mulinari, D. (eds.) (2009), Complying with Colonialism. Gender, Race and Ethnicity in the Nordic Region. Farnham: Ashgate.

Knowles, C. (2003), Race and Social Analysis. London: SAGE

Larsen, N. (1929) Passing. New York, London: A. A. Knopf.

Lather, P. (2007), Getting Lost. Feminist Efforts toward a Double(d) Science. New York: SUNY Press.

Lewis, G. (2006), Journeying Toward the Nation(al): Cultural Difference at the Crossroads of Old and New Globalizations, Mobilities 1(3): 333-352.

Luling, V. (2006), Genealogy as Theory, Genealogy as Tool: Aspects of Somali 'Clanship', Social Identities, Journal for the Study of Race, Nation and Culture 12(4):471-485.

McClinktock, A. (1995), Imperial Leather: Race, Gender and Sexuality in the Colonial Contest. New York: Routledge.

Maynard, M. (1994), Methods, Practice and Epistemology: The Debate about Feminism and Research, in M. Maynard and J. Purvis (Eds.) Researching Women's Lives from a Feminist Perspective. London: Taylor and Francis.

McCarthy, T. (2000), The Stolen Generation, Time Magazine, US. Oct $2^{\text {nd }} 2000$, http://www.time.com/time/magazine/article/0,9171,998067,00.html, last viewed Feb $6^{\text {th }} 2012$

Modood, T., Berthoud, R. and Nazroo, J. (2002), 'Race', Racism and Ethnicity: A Response to Ken Smith, Sociology 36(2): 419-427.

Nagar, R. and Geiger, S. (2007), Reflexivity and Positionality in Feminist Fieldwork Revisited, in Adam Tickell, Eric Sheppard, Jamie Peck and Trevor Barnes (Eds.) Politics and Practice in Economic Geography. London: Sage. Available at:

http://www.tc.umn.edu/ nagar/documents/NagarandGeigerfinaldraftReflexivityandPositionalit yinFeministFieldworkjan07.pdf, last viewed on March 14th 2012.

Phoenix, A. (1994), Practising feminist research: the intersection of gender and race in the research process, in M. Maynard and J. Purvis (Eds.) Researching Women's Lives from a Feminist Perspective. London: Taylor \& Francis.

Read, P. (2006, [1981]), The Stolen Generations; The removal of Aboriginal children in New South Wales 1883 to 1969, Surry Hills: New South Wales Department of Aboriginal Affairs. 
Roth, P. (2000) The Human Stain. Boston: Houghton Mifflin Harcourt.

Spivak, G. (1988), Can the Subaltern Speak?, in Nelson, C. and Grossberg, L. (eds.), Marxism and the Interpretation of Culture, Basingstoke: Macmillan Education, pp. 271-313.

St Louis, B. (2005), The difference sameness makes: Racial recognition and the 'narcissism of minor differences', Ethnicities 5(3):343-364.

Twine, F.W. and Gallagher, C. (2008), The future of whiteness: a map of the 'third wave', Ethnic and Racial Studies 31(1):4-24.

Ware, V. (2002), Otherworldly Knowledge: Towards a Language of 'Perspicuous Contrast', pp. 15-32 in Back, L. and Ware, V. (eds.) (2002), Out of Whiteness: Color, Politics and Culture, Chicago: University of Chicago Press.

\section{Authors}

madeleine kennedy-macfoy is a Visiting Researcher at the Centre for Gender Research, University of Oslo, Norway. Email: madeleine.kennedy-macfoy@stk.uio.no

Helene Pristed Nielsen is Associate Professor in Globalisation, Gender Equality and Diversity at the Department of Culture and Global Studies at Aalborg University, Denmark. Email: pristed@cgs.aau.dk 